\title{
Periodontal condition in patients of the specialist Outpatient Clinics at the Institute of Rural Health in Lublin, Poland
}

\author{
Agnieszka Pawłowicz', Teresa Bachanek', Magdalena Klijer', Renata Chałas ${ }^{1}$ \\ ${ }^{1}$ Department of Conservative Dentistry and Endodontics, Medical University of Lublin, Poland \\ Pawłowicz A, Bachanek T, Klijer M, Chałas R. Periodontal condition in patients of the specialist Outpatient Clinics at the Institute of Rural \\ Health in Lublin, Poland. Ann Agric Environ Med. 2018; 25(1): 9-12. doi: 10.5604/12321966.1227649
}

\begin{abstract}
Introduction. Periodontal disease is a chronic inflammation which, if remains untreated, can lead to the loss of teeth and supporting structures. Evidence data support the relationship of periodontal disease with the development and course of diseases such as heart attack, stroke, hypertension, chronic renal diseases, rheumatoid arthritis or diabetes.

Objective. The aim of the study was to conduct an assessment of periodontal status and periodontal needs in people from the rural environment who were patients of selected specialist outpatient clinics at the Institute of Rural Health in Lublin, Poland.

Materials and methods. The examined population included 450 patients. The Community Periodontal Index of Treatment Needs, which is a measure of the assessment of the selected periodontal symptoms incidence, was used. The obtained data was discussed and analyzed with Chi-square test.

Results. The data obtained revealed that a healthy periodontium occurred only in $5.1 \%$ of respondents, tartar in $41.6 \%$, pathological pockets of $3.5-5.5 \mathrm{~mm}$ in $23.6 \%$, and pockets deeper than $5.5 \mathrm{~mm}$ in $5.8 \%$ of patients. Most people with healthy periodontium were in the youngest age group. In the analyzed group, $7.1 \%$ of patients required specialized comprehensive periodontal treatment, and only $6.5 \%$ of the examined persons did not show any need for periodontal treatment.

Conclusions. Patients of specialist clinics of the Institute of Rural Health who formed the analyzed group, had affected periodontium which required comprehensive periodontal treatment. The alarmingly high percentage of people over 55 years of age with advanced periodontopathy may translate into an increased risk of cause-and-effect incidence of systemic diseases.
\end{abstract}

\section{Key words}

periodontal diseases, Community Periodontal Index of Treatment Needs (CPITN), systemic diseases

\section{INTRODUCTION}

Periodontal disease, such as periodontitis, is one of the most chronic infectious diseases and, among dental diseases in humans, it is the most common after tooth decay. The inflammatory process involves the soft tissues and bone surrounding the teeth in the jaws. Periodontitis is often associated with extensive biofilm formation on the tooth and gingival interface. The biofilm is mainly dominated by anaerobic, Gram-negative bacteria. The mouth is an ideal area for them and more than 700 species of bacteria are estimated to be found in the oral cavity, and the people affected by periodontal diseases are at increased risk of potentially fatal bacteria entering the bloodstream via infected oral tissues. Therefore, periodontitis as a chronic inflammation can be linked to many serious systemic diseases. Increasing data supports the relationship of periodontal disease to the development and course of diseases, such as heart attack, stroke, hypertension, chronic renal diseases, rheumatoid arthritis or diabetes $[1,2,3,4,5,6,7,8]$. Therefore, each patient of specialist clinic, particularly those with ischemic heart disease, stroke or hypertension, should be referred to expert dental consultation to have the state of oral health and possible presence of periodontal disease assessed $[9,10]$.

Address for correspondence: Renata Chałas, Department of Conservative Dentistry and Endodontics, Medical University of Lublin, Karmelicka 7, 20-081 Lublin, Poland e-mail: renata.chalas@umlub.pl

Received: 12 July 2014; accepted: 10 March 2015; first published on December, 2016
The Specialist and Occupational Diseases Clinics at the Institute of Rural Health in Lublin carry out a therapeutic, diagnostic, consultative, jurisprudence and methodicaldidactic activity, mainly for the rural population in the field of allergy, vascular surgery, metabolic diseases, internal medicine, diabetes, endocrinology, gastroenterology, cardiology, neurology and rheumatology, among others. However, the specific character of specialist clinics of the Institute of Rural Health does not always guarantee dental examination. Therefore, the physician is obliged to refer the patient to a dentist, especially if the patient is not covered by dental care and a dental examination had not been implemented within the last six months. The physician's attention should be directed to anxiety symptoms, such as pain, swelling and bleeding of gums, and teeth mobility, since the bacteria present in the oral cavity in patients with periodontal disease may be the source of pathogenic factors activating the immune and inflammatory response of the host. The data obtained from many studies also suggests that periodontal changes can be the first clinical manifestation of, for example, diabetes. Evidence also suggests diabetes as a risk factor for gingivitis and chronic periodontitis [11, 12]. Offenbacher et al. observed that the progression of periodontal destruction was associated with an increase in the prostaglandin E2 levels in the gingival fluid. This would further lead to the local production of cytokines in the periodontal pocket [13]. The local increase of inflammatory mediators such as IL-1, IL- 6 and TNF- $a$ therefore has not 
only local significance, but may also be a risk factor for the development of systemic diseases. These cytokines play an important role in the formation of lesions leading to the development of atherosclerotic plaques, and are also linked by other factors with the coagulation system - fibrinolysis. This creates a dangerous situation for general health, where adult patients more frequently and for a longer time suffer from active inflammatory periodontopathy, the harmful effects of which to health have been so often raised today [1, $14,15,16,17,18]$. The findings of Kumar et al. showed in cases of inflammatory gingival pathology in arterial hypertension that the absolute neutrophil number was significantly higher, proving more acute inflammatory process and a greater amount of tissues involvement. Thus, increased periodontitis in hypertensive patients could probably be attributed as one of the manifestations of hypertension [4].

Older adults in the rural communities have significant oral health disparities [19]. Limited information is available for this population regarding the prevalence of periodontal diseases and the association between state of periodontium and general health. Furthermore, this population has limited access to dental care providers.

In the light of these reports, it seemed purposeful to conduct studies to assess periodontal status in people from the rural environment who were the patients of selected specialist outpatient clinics at the Institute of Rural Health in Lublin, Poland.

\section{MATERIALS AND METHOD}

The examined population included 450 adult rural patients (32.5\% males; $67.5 \%$ females) referred to the cardiology (32.77\%), gastroenterology (17.95\%), orthopedic (29.39\%) endocrinology and diabetic (19.89\%) outpatient clinics, who agreed to have physical examinations of the oral cavity. The examined individuals filled-in the questionnaire concerning past, and self-assessment of their health ('satisfactory', 'unsatisfactory' or 'I don't know'), and underwent clinical examination of the oral cavity. The study was conducted at the Institute of Rural Health in Lublin, in artificial light using dental mirrors and a periodontal probe. Examination of the oral cavity, including state of periodontium was performed by experienced dentists.

For the purpose of this study, the Community Periodontal Index of Treatment Needs (CPITN) was used. This is a measure of assessment of the selected periodontal symptoms incidence (gum bleeding after probing, the presence of dental calculus, periodontal pockets from $3.5-5.5 \mathrm{~mm}$, and pathological periodontal pockets with a depth of at least $6 \mathrm{~mm}$ ) and of the categorization of periodontal treatment needs [20, 21]. A periodontal probe $621 \mathrm{WHO}$ was used for testing. This probe terminates in a ball with a diameter of $0.5 \mathrm{~mm}$, which allows a thorough examination of the surface of each tooth, especially the root cementum. Above the ball, there is a field corresponding to the depth of a gingival pocket of $3.5 \mathrm{~mm}$, which is considered the physiological depth of a periodontal pocket. Above that, there is black field extending to the depth of $3.5-5.5 \mathrm{~mm}$, which corresponds to a pathological gingival pocket. The compression force of the probe during the test should not exceed $25 \mathrm{~g}$. For each tested sextant, periodontal status was determined by the following codes:
Code 0 - no signs of inflammation (CPI-0);

Code 1 - presence of bleeding with gentle probing (CPI-1); Code 2 - presence of supra- and / or subgingival calculus, or overhanging fillings (CPI-2);

Code 3 - presence of pathological periodontal pockets of 3.5 - $5.5 \mathrm{~mm}$ depth (CPI-3);

Code 4 - presence of pathological periodontal pockets of $5.5 \mathrm{~mm}$ and deeper (CPI-4);

Code $\mathrm{X}$ - sextants excluded from examination (less than two teeth present). In each sextant of teeth the highest CPI code value was evaluated.

The maximal value of the index from all of the sextants allowed the following definitions of periodontal treatment needs:

TN0 - patient does not show periodontal treatment needs (Code 0 for all sextants);

TN1 - need for instructing the patient on oral cavity hygiene (Code 1 for at least one sextant);

TN2 - need for professional removal of sediment and tartar from the surface of teeth, correction of filling(s) and removing of all factors increasing plaque retention, instructing on oral cavity hygiene (Code 2 or 3 for at least one sextant);

TN3 - need for complex professional periodontal treatment: surgical treatment, tooth extraction, scaling, instruction on oral cavity hygiene (Code 4 for at least one sextant).

Statistical analyses were performed with the use of SPSS PL v. 12. Significance of the differences was assessed using the Pearson chi-square test. The p-values of the test statistics lower than 0.05 (two-sided) were considered significant.

\section{RESULTS}

Data defining the periodontal status of the rural population of the study group is summarized in Tables 1-3.

Considering the data obtained on the periodontal status in the age groups, it was found that a healthy periodontium occurred in only 23 cases, i.e. in $5.1 \%$ of all examined respondents, tartar occurred in $41.6 \%$, pathological pockets of $3.5-5.5 \mathrm{~mm}$ in $23.6 \%$, and the pockets deeper than $5.5 \mathrm{~mm}$ in $5.8 \%$ of patients. People with sextants excluded from the study accounted for $18.9 \%$. Most people with healthy periodontium $(21.2 \%)$ were in the youngest age group of examined persons, those aged under 35 . In the 35-54 age group, the most commonly found condition was tartar - CPI Code 2, and among those of $\geq 55$ years of age, the highest percentage in the study group (43.4\%) concerned excluded sextants; however, the percentage of sextants with CPI Code 4 was double that in the younger group. The observed differences were statistically significant (Tab. 1).

Considering the data obtained on periodontal treatment needs in the age groups, it was found that in all age groups tested the highest percentage of people qualified for secondclass medical needs in the treatment of periodontium Code TN2, respectively ( $<35$ years $-62.8 \%, 35-54$ years $-87.4 \%, \geq 55$ years $-79.8 \%$ ). These individuals, in addition to appropriate oral hygiene instructions, required removal of tartar with possible curettage of pathological pockets and correction of overhanging fillings. In the analyzed group, $7.1 \%$ of patients required specialized comprehensive periodontal treatment 
Table 1. Community Periodontal Index in the examined population

\begin{tabular}{|c|c|c|c|c|c|}
\hline \multirow[b]{2}{*}{$\mathrm{CPI}$} & & \multicolumn{3}{|c|}{ Age } & \multirow[b]{2}{*}{ Total } \\
\hline & & $\leq 34$ years & $\begin{array}{c}35-54 \\
\text { years }\end{array}$ & $\geq 55$ years & \\
\hline Healthy & $\mathrm{n}$ & 18 & 5 & 0 & 23 \\
\hline CPI 0 & $\%$ & $21.2 \%$ & $2.3 \%$ & $0.0 \%$ & $5.1 \%$ \\
\hline Bleeding & $\mathrm{n}$ & 14 & 9 & 0 & 23 \\
\hline CPI 1 & $\%$ & $16.5 \%$ & $4.1 \%$ & $0.0 \%$ & $5.1 \%$ \\
\hline Calculus & $\mathrm{n}$ & 42 & 107 & 38 & 187 \\
\hline $\mathrm{CPI} 2$ & $\%$ & $49.4 \%$ & $48.6 \%$ & $26.2 \%$ & $41.6 \%$ \\
\hline Pocket $3.5-5.5 \mathrm{~mm}$ & $\mathrm{n}$ & 11 & 66 & 29 & 106 \\
\hline CPI 3 & $\%$ & $12.9 \%$ & $30.0 \%$ & $20.0 \%$ & $23.6 \%$ \\
\hline Pocket $\geq 5.5 \mathrm{~mm}$ & $\mathrm{n}$ & 0 & 11 & 15 & 26 \\
\hline CPI 4 & $\%$ & $0.0 \%$ & $5.0 \%$ & $10.3 \%$ & $5.8 \%$ \\
\hline Excluded sextant & $\mathrm{n}$ & 0 & 22 & 63 & 85 \\
\hline$x$ & $\%$ & $0.0 \%$ & $10.0 \%$ & $43.4 \%$ & $18.9 \%$ \\
\hline \multirow[t]{2}{*}{ Total } & $\mathrm{n}$ & 85 & 220 & 145 & 450 \\
\hline & $\%$ & $100.0 \%$ & $100.0 \%$ & $100.0 \%$ & $100.0 \%$ \\
\hline
\end{tabular}

CPI * Age; Chi-Square test $=189.915 ; \mathrm{p}<0.001$.

Table 2. Periodontal Treatment Needs in examined population

\begin{tabular}{|c|c|c|c|c|c|c|}
\hline & & & \multicolumn{3}{|c|}{ Age } & \multirow[t]{2}{*}{ Total } \\
\hline & & & $\leq 34$ years & $\begin{array}{l}35-54 \\
\text { years }\end{array}$ & $\geq 55$ years & \\
\hline \multirow[t]{8}{*}{ TN } & TNO & $\mathrm{n}$ & 18 & 5 & 1 & 24 \\
\hline & & $\%$ & $20.9 \%$ & $2.5 \%$ & $1.2 \%$ & $6.5 \%$ \\
\hline & TN1 & $\mathrm{n}$ & 14 & 9 & 1 & 24 \\
\hline & & $\%$ & $16.3 \%$ & $4.5 \%$ & $1.2 \%$ & $6.5 \%$ \\
\hline & TN2 & $\mathrm{n}$ & 54 & 173 & 67 & 294 \\
\hline & & $\%$ & $62.8 \%$ & $87.4 \%$ & $79.8 \%$ & $79.9 \%$ \\
\hline & TN3 & $\mathrm{n}$ & 0 & 11 & 15 & 26 \\
\hline & & $\%$ & $0.0 \%$ & $5.6 \%$ & $17.8 \%$ & $7.1 \%$ \\
\hline \multirow[t]{2}{*}{ Total } & & $\mathrm{n}$ & 86 & 198 & 84 & 368 \\
\hline & & $\%$ & $100.0 \%$ & $100.0 \%$ & $100.0 \%$ & $100.0 \%$ \\
\hline
\end{tabular}

TN * Age; Chi-Square test $=76.275 ; \mathrm{p}<0.05$

Table 3. Health self-assessment and Community Periodontal Index among examined subjects

\begin{tabular}{lcccc}
\hline \multirow{2}{*}{ CPI } & \multicolumn{3}{c}{ Health self-assessment } & \multirow{2}{*}{ Total } \\
\cline { 2 - 4 } & Satisfactory & Unsatisfactory & I don'tknow & \\
\hline Healthy & 15 & 4 & 4 & 23 \\
CPI 0 & $10.3 \%$ & $2.0 \%$ & $3.8 \%$ & $5.1 \%$ \\
\hline Bleeding & 15 & 6 & 2 & 23 \\
CPI 1 & $10.3 \%$ & $3.0 \%$ & $1.9 \%$ & $5.1 \%$ \\
\hline Calculus & 57 & 87 & 43 & 187 \\
CPI 2 & $39.0 \%$ & $43.7 \%$ & $41.0 \%$ & $41.6 \%$ \\
\hline Pocket 3.5-5.5mm & 27 & 47 & 32 & 106 \\
CPI 3 & $18.5 \%$ & $23.6 \%$ & $30.5 \%$ & $23.6 \%$ \\
\hline Pocket $\geq 5.5 \mathrm{~mm}$ & 3 & 13 & 10 & 26 \\
CPI 4 & $2.1 \%$ & $6.5 \%$ & $9.5 \%$ & $5.8 \%$ \\
\hline Excluded sextant & 29 & 42 & 14 & 85 \\
X & $19.9 \%$ & $21.1 \%$ & $13.3 \%$ & $18.9 \%$ \\
\hline Total & 146 & 199 & 105 & 450 \\
\hline
\end{tabular}

(TN3), and only $6.5 \%$ of the examined persons did not show any periodontal treatment needs. Statistically significant differences were observed (Tab. 2).

The examined persons were additionally asked to assess their own health by answering: 'satisfactory', 'unsatisfactory' or 'I don't know'. In connection with the state of periodontium, it was found that rural people with bad condition of periodontal tissues (Code CPI 2 and 3) assessed their health as unsatisfactory $-43.7 \%$ and $25.5 \%$, respectively. Only $10.3 \%$ of respondents with healthy periodontium defined their health as satisfactory. Rural people who could not assess their health ('I don't know') were the third group in the presented study (Tab. 3).

\section{DISSCUSSION}

The number of studies on the relationship between oral disease and systemic health has increased in recent years [2, $3,4,6]$; in particular, interest in metabolic syndrome and oral health conditions, such as periodontitis, has been growing. Numerous epidemiological associations link chronic periodontitis to age-associated and biologically complex conditions, such as diabetes, osteoporosis, respiratory diseases, rheumatoid arthritis, certain cancers, erectile dysfunction, kidney diseases and dementia [22]. The most significant studies carried out in recent years have linked chronic inflammation of the oral cavity to development of cardiovascular diseases. Some of them have shown that periodontal treatment favourably modifies the endothelial function, inflammatory markers, or the thickness of the intima-media complex of carotid arteries that directly correlate with the severity of atherosclerosis, and increase the risk of significant cardiovascular events $[15,16,17,18]$. With age, the percentage of patients with periodontal diseases and the extent and severity of the process of connective tissue attachment loss increases: up to 60 years of age, severity of the disease increases, in the age range 60-80, it stabilizes, and after 80 years of age, it is reduced. But if the periodontitis is left untreated, it can affect the tooth supporting structures and lead to tooth loss [23].

A healthy periodontium is vital for the general well-being of individuals, and assessment of the periodontal condition is made with the CPITN index, introduced by the World Health Organization (WHO). This index is used in most countries worldwide in order to estimate the prevalence of easily identifiable symptoms of periodontal disease, to determine the needs for treatment, together with a range of medical and preventive activities for the patient, dental hygienist, dentist and specialist periodontist. Based on this index, periodontal goals for 2010 have been defined by the WHO, and for adults aged 35-44 years, the following assumptions have been identified:

1) not more than $2 \%$ of toothless people;

2) $90 \%$ with a minimum of 20 functionally efficient teeth;

3) no more than an average of 0.25 sextant with CPI 4 [24].

It is worth emphasizing that the first two objectives have been achieved. However, the third goal, on the average number of sextants with the deepest periodontal pockets, has not been attained, and the percentage of people in Poland requiring comprehensive periodontal treatment is very high $-16.5 \%$. The results of this study confirm that 
periodontopahties are now social diseases in adult Poles [5].

In the light of these reports, the attempt to assess the periodontal condition in own research regarding those rural residents who make use of various forms of medical care was justified. The results of the study show that only $5.1 \%$ of the rural population referred to specialist outpatient clinics had healthy periodontium, and most patients with unhealthy periodontium (CPI 2 and 3) assessed their health condition as unsatisfactory. This is in agreement with a study by Lee at al. [25] who examined the relationship between components of metabolic syndrome and periodontal disease in Korean elders living in rural areas. The results showed that there was a significant association between the morbidity duration of metabolic syndrome and CPI indexes with the risk of periodontal disease being increased [25].

This situation creates a dangerous risk for general health, especially for a patient prone to such disease such as coronary heart disease, hypertension and diabetes. This sets particular tasks for dentists. The activities of primary health care units should, however, focus on those people who do not report to treatment and control. People referring to dentists already have some degree of health awareness and perhaps are the best-motivated members of the community. However, a dentist is always obliged to obtain the history of a patient suffering from periodontal disease about cardiovascular diseases, hypertension and diabetes, and proper periodontal examination and care should be an integral part of medical care among patients in the high risk groups $[1,8,10]$. In subsequent years, it seems possible that additional associations will be reported, despite adjustments for known genetic, behavioural and environmental confounders [22]. Therefore, medical and dental professionals need to coordinate the care for systemic diseases and the oral health for these people.

\section{CONCLUSION}

The data obtained from the analyzed group of patients of specialist clinics at the Institute of Rural Health, revealed that the number of people with affected periodontium requiring comprehensive periodontal treatment increases with age.

\section{REFERENCES}

1. Górska R. Relationship between periodontitis and systemic disorders. Dent Med Probl. 2009; 46(4): 379-383.

2. Kowalski J. Genetic and microbiological verification of generalized chronic periodontitis and generalized aggressive periodontitis. Dent Med Probl. 2012; 49(3): 370-376.
3. Leong XF, Ng ChY, Nadiah B, Das S. Association between hypertension and periodontitis: possible mechanisms. Sci World J. 2014; http://dx.doi. org/10.1155/2014/768237.

4. Kumar P, Mastan KMK, Chowdhary R, Shanmugam K. Oral manifestations in hypertensive patients: A clinical study. J Oral Maxillofac Pathol. 2012; 16(2): 215-221.

5. Górska R, Pietruska M, Dembowska E, Wysokińska-Miszczuk, Włosowicz M, Konopka T. Prevalence of periodontal diseases in 35-44 years-olds in the large urban agglomerations. Dent Med Probl. 2012; 49(1): 19-27.

6. Koszuta A, Szymańska J, Kubić-Filiks B. Patients with systemic diseases treated with dental implants. Pol J Public Health. 2013; 123(4): 305-306.

7. Kłosińska A, Nowacka M, Kopeć G, Zarzecka J, Loster B, Pająk A, Podolec P. Periodontitis and the risk of cardiovascular diseases - review of epidemiological studies. Kardiol Pol. 2012; 68(8): 973-976.

8. Sanz M, vanVinkelhoff AJ, Working Group 1 of Seventh European Workshop on Periodontology. Periodontal infections: understanding the complexity - consensus of the Seventh European Workshop on Periodontology. J Clin Periodontol. 2011; 38(suppl 11): 3-6.

9. Vrotsos JA, Vrahopulos TP. Effect of systemic diseases in the periodontium. Curr Opin Periodontol. 1996; (3): 19-26.

10. Krebs KA, Clem DS $3^{\text {rd }}$. Guidelines for the management of subjects with periodontal diseases. J Periodontol. 2006; 77(9): 1607-1611.

11. Mealey BL, Oates TW. Diabetes mellitus and periodontal diseases. J Periodontol. 2006; 77(8): 1289-1303.

12. Kiran M, Arpak N, Unsal E, Erdoğan MF. The effect of improved periodontal health on metabolic control in type 2 diabetes mellitus. J Clin Periodontol. 2005; 32(3): 266-272.

13. Offenbacher S, Barros SP, Beck JD. Rethinking periodontal inflammation. J Periodontol. 2008, 79(8 Suppl): 1577-1584.

14. Tonetti MS. Periodontitis and risk for atherosclerosis: an update on intervention trials. J Clin Periodontol. 2009; 36(suppl. 10): 15-19.

15. D’Aiuto F, Nibali L, Parkar M, Suvan J, Tonetti MS. Short-term effects of intensive periodontal therapy on serum inflammatory markers and cholesterol. J Dent Res. 2005; 84(3): 269-273.

16. Zaremba M, Górska R. Periodontal disease as a potential risk factor for cardiovascular diseases. Kardiol Pol. 2008; 66(10): 1102-1106.

17. Tonetti MS, D’Auito F, Nibali L, Donald A, Storry C, Suvan J, Hingorani AD, Vallance P, Deanfield J. Treatment of periodontitis and endothelial function. N Engl J Med. 2007; 356(9): 911-920.

18. Niedzielska I, Janic T, CierpkaSz, Świętochowska E. The effect of chronic periodontitis on the development of atherosclerosis: review of the literature. Med Sci Monit. 2008; 14(7): RA103-106.

19. Bell RA, Arcury TA, Anderson AM, Chen H, Savoca MR, Gilbert GH, Quandt SA. Dental anxiety and oral health outcomes among rural older adults. J Public Health Dent. 2012; 72(1): 53-59.

20. Ainamo J, Barmes D, Beagrie G, Cutress T, Martin J, Sardo-Infirri J. Development of the World Health Organization (WHO) community periodontal index of treatment needs (CPITN). Int Dent J. 1982; 32(3): 281-291.

21. Oral Health Surveys. Basic Methods. WHO Geneva 1997.

22. Otomo-Corgel J, Pucher JJ, Rethman MP, Reynolds MA. State of the science: chronic periodontitis and systemic health. J Evid Base Dent Pract. 2012; 12(3 Suppl): 20-28.

23. Mariño R, Giacaman RA. Factors related to unmet oral health needs in older adults living in Chile. Arch Gerontol Geriatr. 2014; 58(3): 454-459.

24. Banach J. What about execution of periodontal global goals for the year 2010 in Poland? Dent Med Probl. 2002; 39(1): 9-12.

25. Lee KS, Kim EK, Kim JW, Choi YH, Mechant AT, Song KB, Lee HK. The relationship between metabolic conditions and prevalence of periodontal disease in rural Korean elderly. Arch Gerontol Geriatr. 2014, 58(1): 125-129. 